TECHNICAL TRANSACTIONS 7/2017

CZASOPISMO TECHNICZNE 7/2017

MECHANICS

DOI: $10.4467 / 2353737$ XCT.17.122.6663

\author{
Piotr Woś (wos@tu.kielce.pl) \\ Ryszard Dindorf (dindorf@tu.kielce.pl) \\ Department of Machine TechnologyManufacturing Engineering and Metrology, \\ Faculty of Mechatronics and Machine Building, Kielce University of Technology
}

\title{
VIRTUAL PROTOTYPING OF ELECTRO-HYDRAULIC PARALLEL MANIPULATOR CONTROL SYSTEMS
}

WIRTUALNE PROTOTYPOWANIE UKEADU STEROWANIA ELEKTROHYDRAULICZNEGO MANIPULATORA RÓWNOLEGŁEGO

\begin{abstract}
The paper presents the process of virtual prototyping of a parallel manipulator which uses electro-hydraulic servo-mechanisms to drive active elements. A mechatronic solution of tasks of forward and inverse kinematics with the use of a virtual model of the manipulator, as well as a control system for the virtual machine were presented herein. The solution presented in the article makes it possible to study the functions of the control system before its merger with a real manipulator. At the same time, the design process is significantly accelerated.
\end{abstract}

Keywords: virtual prototyping, electro-hydraulic parallel manipulator, rapid control prototyping

\section{Streszczenie}

W artykule zaprezentowano proces wirtualnego prototypowania manipulatora o konstrukcji równoleglej, w którym do napędów członów aktywnych wykorzystano serwomechanizmy elektrohydrauliczne. Przedstawiono mechatroniczne rozwiązanie zadań kinematyki z zastosowaniem wirtualnego modelu manipulatora. Zaproponowane w artykule rozwiązanie umożliwia badanie funkcji układu sterowania przed jego połączeniem zrzeczywistym manipulatorem Jednocześnie proces projektowania zostaje znacząco przyspieszony. Słowa kluczowe: wirtualne prototypowanie, elektrohydrauliczny manipulator równoległy, szybkie prototypowanie układów sterowania 


\section{Introduction}

Virtual prototyping is applied to designing, optimization, validating and digital visualization of the structure. By using the right software, different design concepts can be assessed before incurring any costs of physical prototypes. During the design works, the effect of moveable parts, accuracy of control algorithms, simulation of the electrical control circuits and behavior of the control system in a dedicated machine environment might be evaluated. During this process, it is possible as well to evaluate the behavior of the system in connection with the control and to simulate the virtual system. Virtual prototyping makes it possible to verify projects with regard to the following criteria: strength, stability, collision, ergonomics and safety. The initial stage of the project is to specify the objectives and research, including an analysis of the existing structures used for similar tasks, both with regard to theoretical and practical aspects [5] and [6]. The result of this analysis is a preliminary acceptance of the existing solution as a basis for further work, if the requirements of the project (Fig. 1) are met [1].

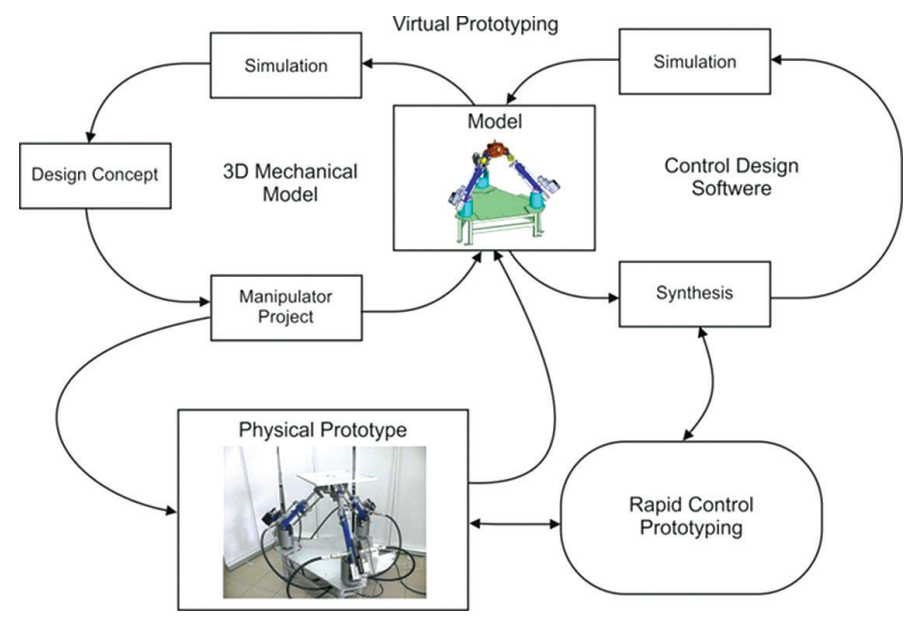

Fig. 1. The procedure of the manipulator design

As a result of these actions, the concept of a manipulator, including kinematics and basic solutions of mechanical and control structure is created [8]. The next step of the procedure is virtual prototyping, including designing and modelling of the structural and electromechanical manipulator, and a synthesis of the control system. During this process, movement of a robot model in an open system, as well as with a driver in the feedback loop is verified. This model includes all elements of the robot: mechanics (kinematics and dynamics), drivers, sensors, control and interaction with the environment. When the virtual manipulator becomes compliant with the assumptions, a physical prototype can be initiated. This manipulator prototype can be used in an identification experiment to tune the model assigned to the assumed control algorithm. A physical prototype is also used with rapid prototyping of the control algorithm. This phase is designed to test the effectiveness of the 
control algorithm during work in real time and to tune its parameters precisely. When the control performance is satisfactory, the control algorithm on a target hardware platform can be implemented. The project of the manipulator construction in the process of virtual prototyping included the following: formulation of equations describing forward and inverse tasks of the manipulator with a parallel structure and three degrees of freedom, analysis of kinematic structures of a hydraulic parallel manipulator, project of a solid manipulator in 3D CAD software, formulation of dependencies which allow for building a dynamic model of the manipulator, a manipulator prototype with electro-hydraulic axes, development of the manipulator control system, implementation of control algorithm in Matlab/Simulink environment, simulation and verification of the control algorithm, rapid prototyping of the control system and its experimental verification on a real object, verification of the control system operation on a physical manipulator model, experimental studies and an analysis and evaluation of the test results of the parallel manipulator.

\section{The design of the parallel manipulator}

The prototype of a three-axis electro-hydraulic manipulator with a parallel structure was designed and manufactured in the Division of Mechatronic Devices at the Kielce University of Technology. The entire structure was developed as a test and academic stand, and was dedicated to study the multidimensional algorithms to control the electro-hydraulic servo-mechanisms [2].

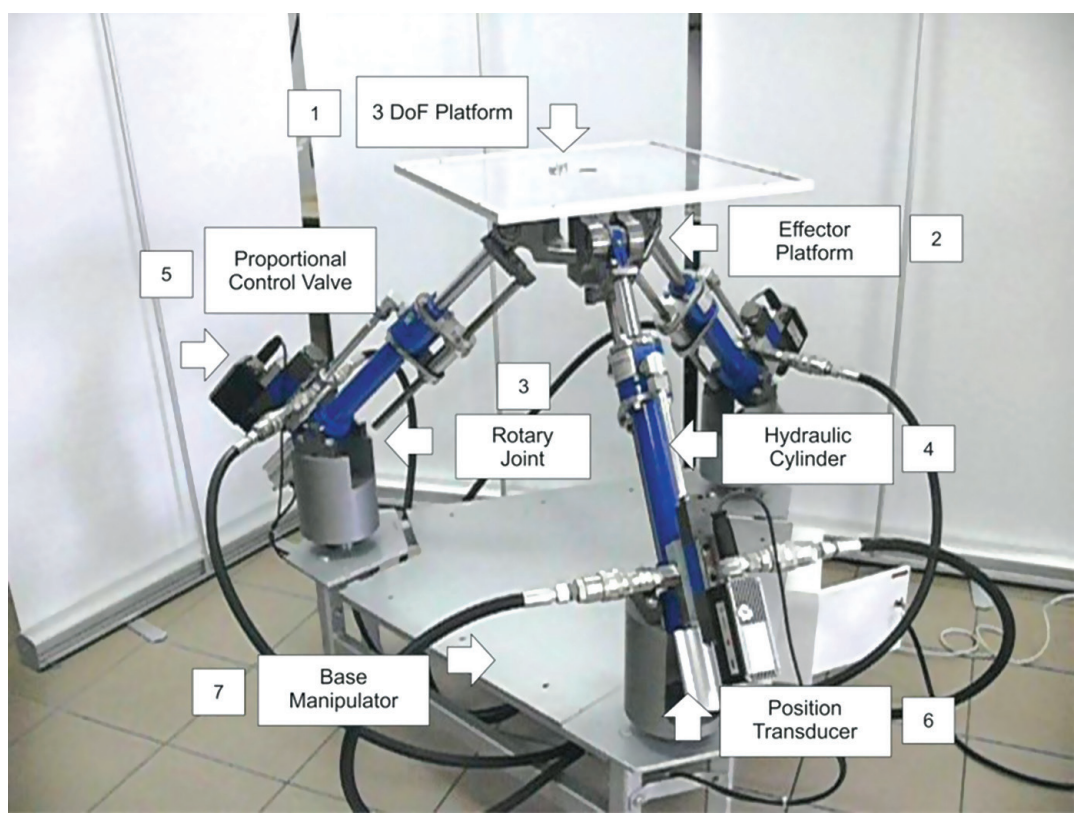

Fig. 2. Manipulator test stand: 1 - hydraulic cylinder 2 - proportional valve, 3 - mobile end-effector platform, 4 - mounting of the manipulator arm, 5 - base manipulator. 
The structure of the manipulator presented in this paper is an original solution regarding the application of electro-hydraulic drives for the manipulator with a parallel structure. Figure 2 shows a prototype of the manipulator. The manipulator is placed on a base (7) in the shape of an equilateral triangle. The base apices contain rotating sleeves that make it possible to mount the joint connecting the actuator with the base (3). Active elements of the manipulator include three identical electro-mechanic servo-mechanisms (4). Electro-hydraulic proportional control separators 4/3 (5) were mounted to the actuators. Magnetostrictive sensors were used to determine the position of particular piston rods of the actuators (6).

\section{Mechatronic solutions of tasks of the kinematics and dynamics of the model}

As far as the design of the mechanical construction of robots is concerned, solutions are sought which will make it possible to use a particular robot in the widest possible range of tasks. In the case of robots with open kinematics, obtaining great flexibility is not a problem, however, as far as the parallel robots are concerned, there is a barrier in the form of design costs and production. This is due to the fact that a parallel robot is comprised of many arms acting directly on the platform. The working space is highly dependent on a range of drive movements and is a common part of all possible positions of each arm. This means that increasing the working space only in one axis is connected with simultaneous increasing of the range of movement of all arms, and thus maintaining adequate stiffness while increasing the dynamics requires the use of better materials or larger cross-sections of structural elements in the places which are most vulnerable to unfavorable tensions. Larger cross-sections mean larger masses which must be moved during work. As a result, any growth of the parameters of a parallel robot associated with space and dynamics increases the cost of the required drives to a much greater extent than it would result from the effects achieved [4].
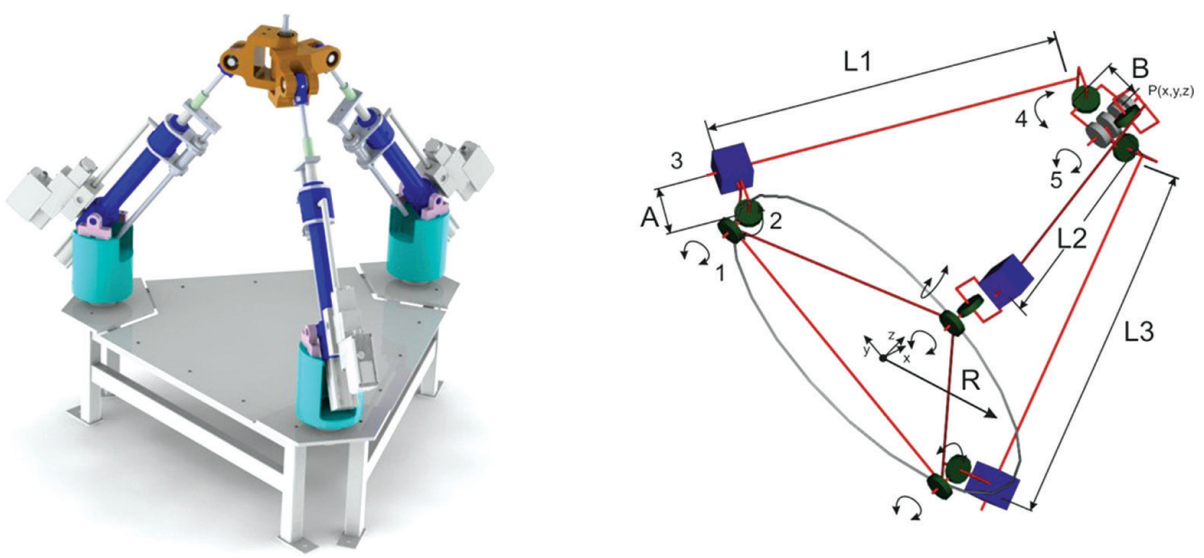

Fig. 3. Kinematic model of the manipulator: 1, 24 and 5 - rotating pairs, L1,2 and 3 - sliding pair 
The basic issue of the analysis of the kinematic structure is a proper planning of the movement trajectory of the manipulator. The task consists in determining the track transition between the starting and end point of the movement of the effector. It is also necessary to determine displacements, velocity and acceleration for movement connections. While designing a manipulator, solving the tasks of forward and inverse kinematics is an important issue. The task of forward kinematics consists in determining the position of a moveable platform and mapping the system position in the configuration of coordinates against the position of the system in Cartesian space. If one acquaints themselves with the set of values of linear and angular displacements of electro-hydraulic servomechanisms of particular movement connections of the manipulator, the position of its executive element can be determined [6]. The task of inverse kinematics is more difficult to solve and consists in determining the values and configuration of particular positions of the drive elements of the manipulator. Knowledge about the orientation and position of the working end in Cartesian space is required. All possible values of linear and angular displacements which are responsible for achieving the present positions and orientation of the manipulator need to be determined. Solving the task of forward and inverse kinematics is essential in positioning, control and control of the manipulator along a specified curve in Cartesian space [4]. Development of the control system of the manipulator is a complex task which requires i.a.: an analysis of the movement parameters of the effector, development of algorithms to determine non-collision drive movement tracks and determination of the working space of the manipulator in the displacement function of its drives. The whole process requires a lot of trials and modifications. That is why the tasks mentioned before were developed during the process of virtual prototyping with the use of SolidWorks software (development of a solid model) and Matlab/Simulink (implementation and test simulation). This allows for

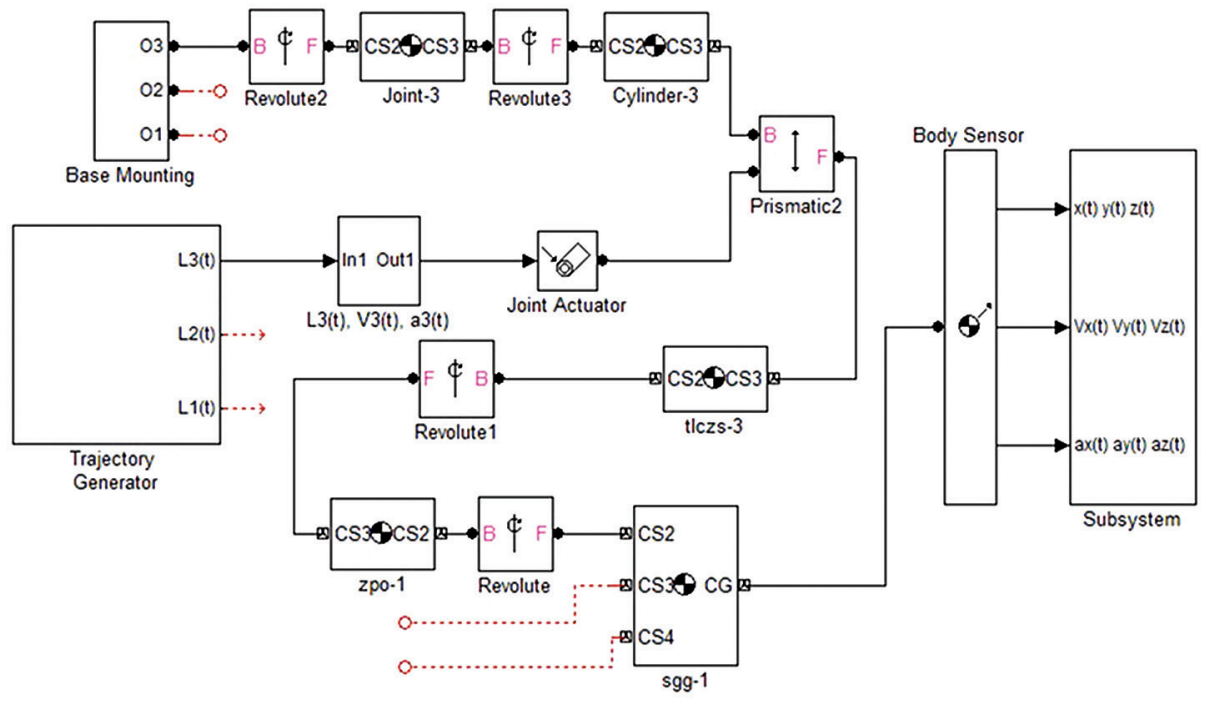

Fig. 4. SimMechanics block diagram - inverse kinematics 
designing a virtual model and checking its behaviour under fixed initial conditions. Thanks to this solution, the design process was significantly streamlined and accelerated. With the use of SimMechanics toolkit, it was possible to import a finished solid model from SolidWorks to Matlab/Simulink, which made it possible to create structures for solutions of forward and inverse kinematics [2]. The block diagram presented in Fig. 4 includes function blocks, i.e.: Revoluta and Prismatic, which provide rotational and translational movements. Moreover, Joint Actuator and Body Sensor allow respectively: force exertion on a generated binding and measurement of the position of the element to which it is connected. The remaining elements of the diagram include physical elements of the manipulator, such as connectors, joints, cylinders and connecting rods containing information about their mass. This software was used to determine the displacement, velocity and acceleration for the centre point connecting particular arms of the manipulator at fixed displacements of the servo-drives.

This model makes it possible to determine the velocity and acceleration in the remaining moveable elements of the structure. Additionally, the software provides visualization of the movement of the manipulator. Figure 5 shows a virtual model of SimMechanics and sample charts of trajectory points of the movement of the manipulator.

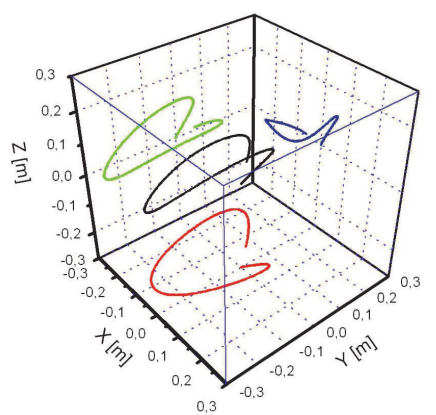

Trajectory $[\mathrm{m}]$

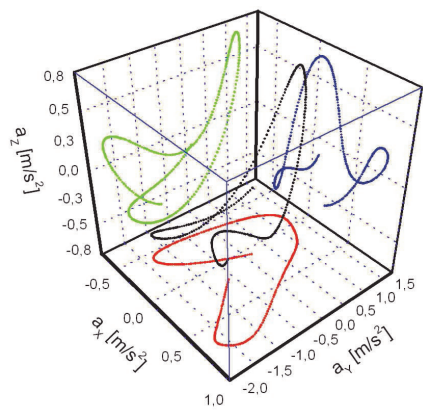

Acceleration $[\mathrm{m} / \mathrm{s} 2]$

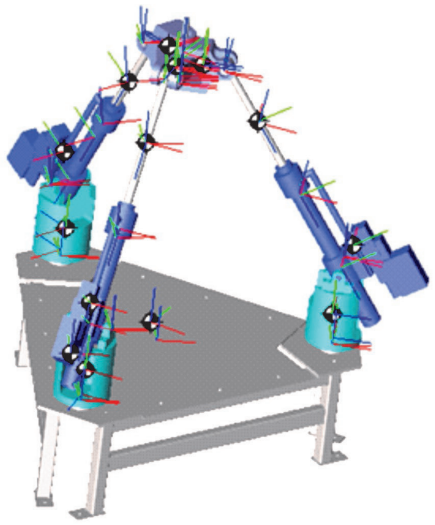

3D Mechanical Model SimMechanics

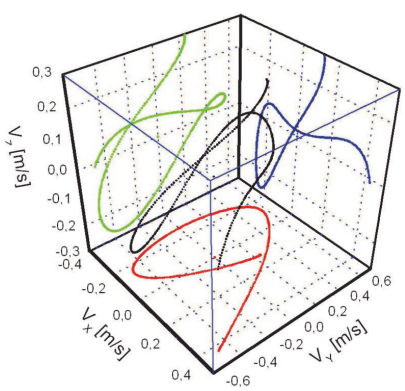

Velocity $[\mathrm{m} / \mathrm{s}]$

Fig. 5. A virtual model of SimMechanics and charts of trajectory points of the movement of the manipulator 


\section{Rapid prototyping of the control system}

Rapid control prototyping (RCP) is treated as real-time simulations and, next to Hardware-in-the-Loop Simulation (HILS) technology, is an important element in the process of design and prototyping of the control systems. Real-time simulation is meant to improve the experimental research due to the application of efficient calculation systems, which, in real-time and on the basis of previously prepared mathematical models, can generate signals corresponding to the simulated device. In Hardware-in-the-Loop technology, on the basis of previously prepared equations, the system simulates the mechanical device in question or a part thereof by generating output signals corresponding to a given object on the basis of the input information received. This method may be used when there is a real driver, but at the same time there is a real danger of damaging the object. In such case, the object is replaced with a simulator, which makes it possible, e.g. to verify the behaviour of the real control system in situations which are difficult to force on a real object due to the associated damage, such as conditions associated with defects or conditions exceeding the permissible parameters. Then, the simulator replaces the real object and thus, the behaviour of the control system might be inspected. A technique which is used more frequently and seems to be more effective is an inverse situation, when the virtual driver simulated on hardware for rapid prototyping co-operates with the real object. Then, while being acquainted with the real object, an individually designed controller can be checked and modified. An important issue which constitutes the basis for rapid prototyping is automation of the code transfer from a virtual desktop (e.g. Simulink diagram) to the device conducting rapid prototyping. Subsequently, the equipment designed for rapid prototyping, which is usually based on signal processors, conducts calculations related to the control right and, in that way, generates signals dedicated for a real object [3]. Additionally, such system often provides additional benefits in the form of the possibility to observe the signals associated with control and registration for the sake of later analyses, and it is usually possible to modify the parameters of the control system during the device operation. The parameters of reinforcement coefficients can be changed in real time in the virtual controller for the individual elements thereof, and by observing the behaviour of the system, satisfactory values can be determined (Fig. 6).

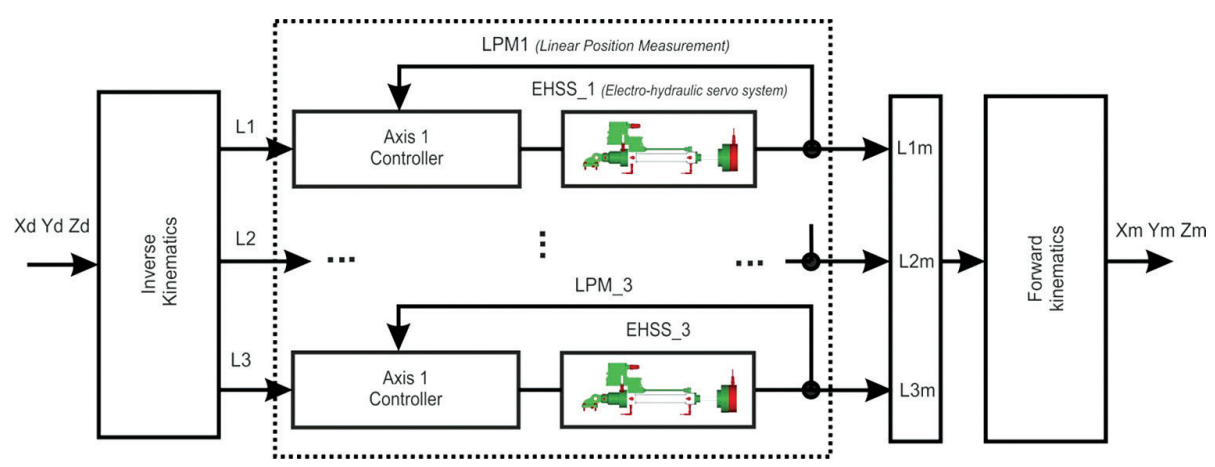

Fig. 6. Block controlled system 
Initial axis controller settings were chosen in an experimental way in the process of virtual prototyping. For this purpose, a multi-mass model developed in SimMechanics software was incorporated into the model of the control system modelled in Matlab/Simulink environment [3]. Axis controller gain coefficients were chosen in such a way so that the position error of the movement trajectory would be minimized. Only after determining the correct coefficient values for the virtual control system was it possible to proceed with the phase of rapid prototyping. During the designing process, it is possible to match the coefficients of the control algorithm directly in the process of rapid control prototyping, however it is safer and more convenient to conduct the experiment with the use of a virtual object. The control system uses the controller designed on hardware for rapid control prototyping (RCP) and XPC Target computer set equipped with $\mathrm{C} / \mathrm{A}$ and $\mathrm{A} / \mathrm{C}$ converter cards of PCI-DAS1602/16 [7].

\section{Experimental results}

In order to show the accuracy of the control system, an experiment on a real object was conducted. In order to obtain wider information about the control quality, different trajectories of movement were studied. Based on distributed measurement and control system, a test stand for rapid prototyping controller of the electro-hydraulic servo-drive was set up [9]. Fig. 7 presents results of the control process for references signals ( $\mathrm{Xd}, \mathrm{Yd}, \mathrm{Zd})$, frequencies $0.16 \mathrm{~Hz}, 0.32 \mathrm{~Hz}, 0.48 \mathrm{~Hz}$ and $0.8 \mathrm{~Hz}$ (Cartesian coordinates).
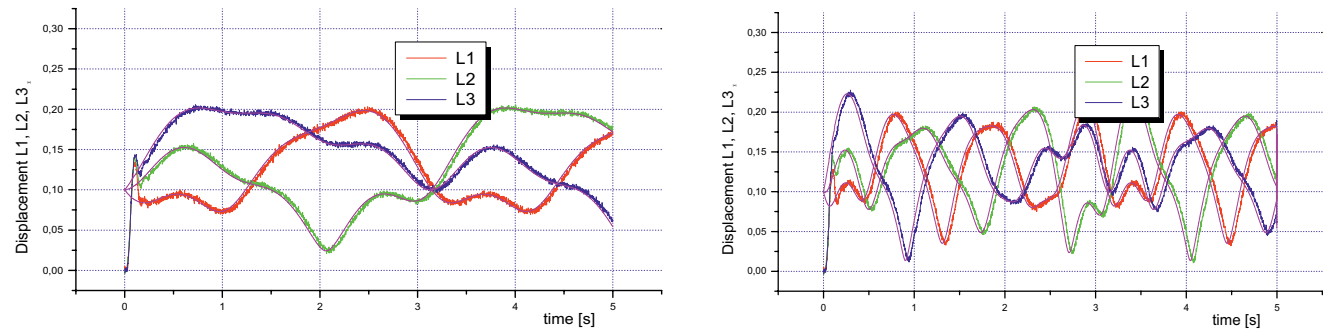

Fig. 7. Displacement of the manipulator arms for control algorithm, according to the sinusoidal reference trajectory in Cartesian coordinates

\section{Summary}

Research on simulation tests on a developed virtual model makes it possible to verify the software controlling the electro-hydraulic manipulator. Due to the results of the simulations, it is possible to introduce some adjustments in the control algorithm and shorten the time of implementation of the control system in a real device. 


\section{References}

[1] Dindorf R., Łaski P., Takosoglu J., Woś P., Rozproszony system sterowania czasu rzeczywistego do serwonapędów plynowych, Czasopismo Techniczne, 4-M/2011, 2011.

[2] Dindorf R., Woś P., Contour error of the 3-DoF hydraulic translational parallel manipulator, Advanced Materials Research, Trans Tech Publications Switzerland, Vol. 874, No. 57, 2014, 57-62.

[3] Dindorf R., Woś P., Szybkie prototypowanie układu regulacji napędu elektrohydraulicznego, Napędy i Sterowanie, Nr 10, 2005, 18-22.

[4] Lung-Wen Tsai, Robot Analysis, The Mechanics of Serial and Parallel Manipulators, John Wiley \& Sons, Inc, 1999.

[5] Tlusty J., Ziegert J., Ridgeway S., Fundamental Comparison of the Use of Serial and Parallel Kinematics for Machine Tools, Annals of the CIRP, 48/1, 1999, 351-356.

[6] Tsai L-W., Robot Analysis, The Mechanics of Serial and Parallel Manipulators, John Wiley \& Sons, New York 1999.

[7] Woś P., Dindorf R., Adaptive control of a parallel manipulator driven by electro-hydraulic cylinders, International Journal of Applied Mechanics and Engineering, Vol. 17, No. 3, 2012.

[8] Woś P., Dindorf R., Łaski P., Takosoglu J., Koncepcja sterowania elektrohydraulicznym manipulatorem typu Tricept, HiP, No. 1, 2011, 9-13.

[9] Woś P., Dindorf R., Synchronized trajectory tracking control of3-DOFhydraulic translational parallel manipulator, Advances of Intelligent System and Computing, Mechatronics Ideas for Industrial Applications, Springer Verlag, Vol. 317, 2015, 269-277. 